Research Paper

\title{
Ophiopogon Saponin C1 Inhibits Lung Tumors by Stabilizing Endothelium Permeability via Inhibition of PKCठ
}

\author{
Yuanyuan Zhang, Yazheng Zhao, Yan Wu, Jin Qi, Fang Li, Junping Kou ${ }^{\varpi}$, Boyang Yu ${ }^{\bowtie}$ \\ Jiangsu Key Laboratory of TCM Evaluation and Translational Research, School of Traditional Chinese Pharmacy, China Pharmaceutical University, 639
} Longmian Road, Nanjing 211198, China.

$\triangle$ Corresponding authors: Dr. Junping Kou \& Dr Boyang Yu; Jiangsu Key Laboratory of TCM Evaluation and Translational Research, School of Traditional Chinese Pharmacy, China Pharmaceutical University, 639 Longmian Road, Nanjing 211198, China, Tel\&Fax: +86- 25- 86185158, E-mail: junpingkou@cpu.edu.cn. (Junping Kou) \& boyangyu59@163.com. (Boyang Yu).

(c) The author(s). This is an open access article distributed under the terms of the Creative Commons Attribution License (https://creativecommons.org/licenses/by/4.0/). See http://ivyspring.com/terms for full terms and conditions.

Received: 2019.03.18; Accepted: 2019.11.12; Published: 2020.01.01

\begin{abstract}
As the most frequent cause of cancer-related death worldwide, lung cancer is closely related to inflammation. The interaction between tumor cells and inflammatory cells promotes tumor development and metastasis. During tumor development, vascular endothelial cells form the most important barrier to prevent tumor cell migration to the blood and tissue. Increased vascular permeability provides favorable conditions for the migration of tumor cells, and endothelial tight junctions are an important component of the vascular barrier. Protein kinase $C \delta$ is involved in the occurrence of non-small cell lung cancer and regulates vascular permeability and tight junction protein expression. Src kinase was reported to play an important role in TNF- $\alpha$-induced endothelial inflammation. Ophiopogon Saponin $\mathrm{Cl}$ is a new chemical compound isolated from Liriope muscari, but its pharmacological activities have not been fully elucidated. Therefore, we tested the protective effects of $\mathrm{Cl}$ on endothelial permeability in a model of TNF- $\alpha$-induced endothelial inflammation by transendothelial electrical resistance and sodium fluorescein assays and verified these results in a nude mouse model of experimental pulmonary adenocarcinoma metastasis. We further elucidated the mechanism of $\mathrm{Cl}$, which was based on the PKC $\delta$ and Src proteins, by Western blotting. $\mathrm{Cl}$ can inhibit lung cancer in vivo, regulate the level of plasma inflammation in tumor-bearing mice, and protect the pulmonary vascular barrier against injury induced by cancer. It was investigated the expression and distribution of the TJ index protein ZO-1 in mouse vascular endothelium and HUVECs and found that $\mathrm{Cl}$ could inhibit the degradation and breakage of the ZO-1 protein. Related signaling experiments confirmed that $\mathrm{Cl}$ can inhibit TNF- $\alpha$ and activation of PKC $\delta$ and Src kinase. This study laid the foundation for further analysis of new drugs with clear mechanisms and independent intellectual property rights of traditional Chinese medicines.
\end{abstract}

Key words: Ophiopogon Saponin C1, Endothelial Cell Permeability, Lung Cancer, TNF-a, PKCס

\section{Introduction}

Malignant neoplastic disease is one of the most common causes of mortality worldwide and has a high rate of death. Among cancers, lung cancer is the most frequent cause of cancer-related death worldwide. Every year, 1.8 million people are diagnosed with lung cancer, and 1.6 million people die due to this disease. The 5 -year survival rates vary from 4 to $17 \%$ depending on the stage and regional differences [1]. Clinical data shown that $80 \%$ of cancer patients died because of tumor metastasis, and thus, control of tumor metastasis is a major strategy for cancer treatment [2]. Age is the single most significant risk factor for cancer development, with the majority of cancer cases being diagnosed after the age of 65 [3]. Aging is a biological process that occurs in virtually all organisms and is characterized by a progressive loss of organ function and decline in tissue renewal capacity [4-6].

Endothelial cells play an important role in tumor metastasis [7]. During tumor metastasis, vascular endothelial cells form the most important barrier to prevent tumor cell migration to the blood and tissue 
[8]. Increased vascular permeability provides favorable conditions for the migration of tumor cells, and endothelial tight junctions (TJs) are an important factor in the vascular barrier. Aging is an important risk factor for the progressive decline of endothelial function [9]. Vascular endothelial dysfunction occurs during the human aging process and is accompanied by deterioration in the balance between vasodilator and vasoconstriction substances produced by the endothelium [10, 11]. Therefore, by protecting endothelial cell integrity, maintaining TJs of endothelial cells, and inhibiting invasion and metastasis of lung cancer cells, effective intervention in the early stage of lung cancer occurrence and metastasis will be an important direction for future research and development of anti-lung cancer metastasis drugs.

ZO-1 is an important cytoplasmic protein that is also a major component of TJs. This protein connects to the main cell body to act as an intermediate transmembrane protein and part of the actin cytoskeleton. Functional and structural changes can cause the dissociation of TJs and an increase in the intercellular space, thereby increasing the vascular permeability $[12,13]$. ZO-1 expression is regulated by a variety of signaling pathways. Previous studies have shown that MAPK, MLC, Src and PKC are involved in the regulation of $\mathrm{ZO}-1$ protein expression [14-16]. Early laboratory studies shown that activation of Src in vascular endothelial cells could activate the PI3K/Akt signaling pathway and mediate the degradation of ZO-1 [17]. Clinical studies reported that PKC $\delta$ is highly expressed in the lung epithelial tissues of non-small cell lung cancer (NSCLC) patients, and its inhibitor rotterlin significantly induced tumor apoptosis, indicating that $\mathrm{PKC} \delta$ is involved in the occurrence of NSCLC [18]. Other studies have shown that $\mathrm{PKC} \delta$ has a role in inflammatory factor-mediated endothelial inflammatory models [19]. PKC $\delta$ can be activated in a Src-dependent manner [20]. Src regulation of PKC $\delta$ has also been reported [21]. However, PKC $\delta$ has little effect on Src, and this interaction has not been reported in vascular endothelial cells.

Our lab extracted the steroidal saponin DT-13 and the aglycone Ruscogin, which were shown to have good anti-inflammatory and anti-tumor activities, from Ophiopogon japonicas [22][23]. Ophiopogon Saponin C1 (C1) is a new compound isolated from the roots of Liriope muscari (Decne.) L.H. Bailey, but its pharmacological effects have not been reported [24]. As to the traditional Chinese medicine theory, the Liriope muscar was used for lung disease. Therefore, in this study, the anti-lung tumor effect of C1 was determined in a nude mouse model of experimental pulmonary adenocarcinoma metastasis, and its mechanism based on the proteins PKC $\delta$ and Src was further elucidated. This study laid foundation for further analysis of new drugs with clear mechanisms and independent intellectual property rights of traditional Chinese medicines.

\section{Materials and Methods}

\section{Extraction and isolation of $\mathbf{C l}$}

C1 was prepared as previously described and identified as $25(\mathrm{R})$-ruscogenin-1-O-[ $\beta$-d-glucopyranosyl-( $(1 \rightarrow 2)][\beta$-d-xylopyranosyl- $(1 \rightarrow 3)]-\beta$-d-fucopyrano side by comparison of its physical data $\left({ }^{1} \mathrm{H}\right.$ NMR, ${ }^{13} \mathrm{C}$ NMR, MS) with published values. The purity was shown to be $98.5 \%$ using HPLC-ELSD assays as previously reported [24].

\section{Cell culture}

HUVECs and A549 cells were purchased from the Shanghai Institute of Cell Biology, Chinese Academy of Sciences. Cells were grown in RPMI 1640 medium (Invitrogen Life Technologies, Carlsbad, CA, USA) supplemented with $10 \%$ heat-inactivated fetal bovine serum (FBS, ScienCell, CA, USA), $100 \mathrm{U} / \mathrm{mL}$ penicillin, $100 \mu \mathrm{g} / \mathrm{mL}$ streptomycin and $2.0 \mathrm{~g} / \mathrm{L}$ sodium bicarbonate. Cells were maintained at $37^{\circ} \mathrm{C}$ with $5 \% \mathrm{CO}_{2}$ and $95 \%$ humidity.

\section{Transendothelial electrical resistance (TEER) assays and sodium fluorescein ( $\mathrm{Na}-\mathrm{F}$ ) assays}

HUVECs were seeded on transwell inserts (0.4 $\mu \mathrm{M}$ pore, $6.5 \mathrm{~mm}$ diameter, Millipore, USA) for 7 days. The TEER of the monolayer was also measured daily with a Millicell-ERS voltohmmeter (Millipore, USA). Resistance values of multiple transwell inserts of an experimental group were measured sequential$1 \mathrm{y}$, and the mean was expressed in the common unit $\left(\Omega \mathrm{cm}^{2}\right)$ after subtraction of the value of a blank cell-free filter. The TEER of the monolayers was recorded when a stable resistance reading was achieved with triplicate measurements that were taken for each transwell. $\mathrm{C} 1(0.01-1 \mu \mathrm{M})$ was added to the upper chamber for $1 \mathrm{~h}$, and $10 \mathrm{ng} / \mathrm{mL}$ TNF- $\alpha$ (Bioworld, USA) was added for $4 \mathrm{~h}$. Paracellular permeability was assessed by the addition of Krebs-Ringer buffer $(118 \mathrm{mM} \mathrm{NaCl}, 4.7 \mathrm{mM} \mathrm{KCl}, 1.3$ $\mathrm{mM} \mathrm{CaCl}_{2}, 1.2 \mathrm{mM} \mathrm{MgCl}_{2}, 1.0 \mathrm{mM} \mathrm{NaH} \mathrm{PO}_{4}, 25 \mathrm{mM}$ $\mathrm{NaHCO}_{3}$, and $11 \mathrm{mM}$ D-glucose, pH 7.4) containing $100 \mathrm{\mu g} / \mathrm{mL} \mathrm{Na}-\mathrm{F}$ to the top chamber. The fluorescence was measured after $30 \mathrm{~min}$ at $37^{\circ} \mathrm{C}$. The $\mathrm{Na}-\mathrm{F}$ concentration was determined using a fluorescence multiwall plate reader [Ex $(\lambda) 485 \mathrm{~nm}$; $\operatorname{Em}(\lambda) 530 \mathrm{~nm}$; Thermo].

\section{Co-culture of A549 and HUVECs}

The $10 \mu \mathrm{g} / \mathrm{mL}$ fibronectin solution was added at 
$100 \mu \mathrm{L} /$ well in an $8 \mu \mathrm{m}$ Millicell chamber and incubated at $4^{\circ} \mathrm{C}$ overnight (Cat\#: PIEP12R48). The well was pretreated with cold PBS 2 3 times. Then, $200 \mu \mathrm{L}$ of HUVECs in the logarithmic growth phase was added in the inner chamber with $1 \mathrm{~mL}$ RPMI 1640 complete medium in the outer chamber. The next day, the medium was changed. After 7 days of continuous culture, $\mathrm{C} 1(0.01-1 \mu \mathrm{M})$ was added to the upper chamber for $1 \mathrm{~h}$, and $10 \mathrm{ng} / \mathrm{mL}$ TNF-a (Bioworld, USA) was added for $4 \mathrm{~h}$. A549 cells in logarithmic growth phase were pretreated by serum-free medium RPMI 1640 for $1 \mathrm{~h}$, and then, the cells were collected and labeled with $1 \mu \mathrm{M}$ Calcein-AM for $15 \mathrm{~min}$. The samples were added to a small inner chamber, and 1 mL RPMI 1640 complete medium was added. After 48 $\mathrm{h}$, the chamber was removed, the cells were carefully wiped out the chamber, and $4 \%$ polyformaldehyde was used to fix the cells at the bottom of the compartment. Then, the chamber with the cells was dried. The migrating cells were observed under a fluorescence microscope.

\section{Animals and experimental design}

Ten-week-old male nude mice were obtained from Yangzhou University (Yangzhou, China). Mice were housed in microisolator cages in a pathogen-free facility. During the logarithmic growth phase, A549 cells were washed 2 times after routine digestion. A 200-cell mesh filter was used to obtain a single cell suspension. The cell concentration was $10^{7}$ cells $/ \mathrm{mL}$ in serum-free DMEM with PBS. The nude mice were inoculated; the tail was soaked for $2 \mathrm{~min}$ at $45^{\circ} \mathrm{C}$ to expand the tail vein, and the A549 single cell suspension was slowly and uniformly injected at a concentration of $10^{6}$ cells $/ 0.1 \mathrm{~mL}$ serum-free DMEM into the tail vein of the nude mice. The mice were weighted after the second day of inoculation. Except for the nude mice in the control group, the other nude mice were randomly divided into 3 groups: the model group, the $\mathrm{C} 1$ administration group and the topotecan hydrochloride (TPT) positive control group. The control group and the model group were treated every day by intragastric administration of $0.5 \% 10$ $\mathrm{g} / 0.1 \mathrm{~mL} \mathrm{CMC}-\mathrm{Na}$, and the drug group was administered $4 \mathrm{mg} / \mathrm{kg} \mathrm{C} 1$ every day by intragastric administration $(0.4 \mathrm{mg} / \mathrm{mL}, 10 \mathrm{~g} / 0.1 \mathrm{~mL}, \mathrm{CMC}-\mathrm{Na}$ $0.5 \%$, dissolved). The positive control group was intravenously injected with $2 \mathrm{mg} / \mathrm{kg}$ TPT $(0.2$ $\mathrm{mg} / \mathrm{mL}, 10 \mathrm{~g} / 0.1 \mathrm{~mL}, \mathrm{CMC}-\mathrm{Na} 0.5 \%$ dissolved) 2 times a week. After the fourth week of inoculation, the model was established. The lung tissue and blood samples were collected, and serum was frozen at $-80^{\circ} \mathrm{C}$ for ELISAs.

\section{Immunofluorescence staining}

The immunofluorescence staining of ZO-1 in vivo was performed as described previously with a few modifications [25]. Aortas from the mice were rapidly excised under general anesthesia, carefully trimmed to remove fat and connective tissue and washed twice by ice-cold PBS. Then, the aortas were opened longitudinally to expose the endothelium and pinned onto $4 \%$ agar. HUVECs were cultured to confluence on glass cover slips in complete media containing 10\% FBS and maintained for 7 days. Cells were then stimulated with TNF- $\alpha(10 \mathrm{ng} / \mathrm{mL})$ for $4 \mathrm{~h}$ with or without prior treatment with $\mathrm{C} 1(1 \mu \mathrm{M})$ for 1 $h$. The aortas or cells were washed with PBS, fixed in $4 \%$ formaldehyde in PBS (v/v) for $30 \mathrm{~min}$ at room temperature, and permeabilized in $0.1 \%$ Triton X-100 in $5 \%$ bovine serum albumin (BSA, diluted in PBS) for $30 \mathrm{~min}$ at room temperature. The aortas or cells were then blocked with $5 \%$ BSA for $1 \mathrm{~h}$ at room temperature. Then, they were incubated with rabbit anti-ZO-1 polyclonal antibody overnight at $4^{\circ} \mathrm{C}$ and washed with PBS three times followed by incubation with donkey anti-rabbit IgG 488-conjugated secondary antibody for $1 \mathrm{~h}$. All samples were assessed using a fluorescence microscope (LSM700, Zeiss, Germany).

\section{Leakage detection of pulmonary vascular permeability in nude mice}

First, $5 \mathrm{mg} / \mathrm{mL}$ EBA solution $(10 \mathrm{~g} / 0.1 \mathrm{~mL})$ was injected into the tail vein in nude mice after establishment of the model, and the mice were anesthetized after $2 \mathrm{~h}$. Then, $5 \mathrm{mM}$ EDTA-PBS solution was used for right ventricular lavage to remove the dye in the blood vessels. The lung tissue was removed and added to filter paper to dry and weigh. Next, $1 \mathrm{~mL}$ formamide solution homogenate was added to 100 $\mathrm{mg}$ lung tissue with liquid nitrogen for quick freezing. The homogenate was transferred into a $1.5 \mathrm{~mL}$ EP tube, and after incubation for $18 \mathrm{~h}$ at $60^{\circ} \mathrm{C}$, the samples was centrifuged at $5000 \mathrm{~g}$ for $30 \mathrm{~min}$. The supernatant was assessed at $620 \mathrm{~nm}$ and $740 \mathrm{~nm}$. At the same time, the -OD value standard curve of EBA was fitted to calculate the EBA content in each lung tissue.

\section{Western blotting}

HUVECs were treated with various concentrations $(0.01,0.1$ and $1 \mu \mathrm{M})$ of $\mathrm{C} 1$ for $1 \mathrm{~h}$ following TNF- $\alpha(10 \mathrm{ng} / \mathrm{mL})$ stimulation for $4 \mathrm{~h}$. After the cells were washed with PBS, they were lysed using lysis buffer (containing $20 \mathrm{mM}$ Tris, $\mathrm{pH}$ 7.5, 150 $\mathrm{mM} \mathrm{NaCl}, 1 \%$ Triton X-100, sodium pyrophosphate, $\beta$-glycerophosphate, EDTA, $\mathrm{Na}_{3} \mathrm{VO}_{4}$, leupeptin) for 30 min on ice. Protein concentration was measured using a BCA protein assay kit. Equal amounts of protein (40 
$\mu \mathrm{g})$ were separated using SDS-PAGE and then transferred onto a PVDF membrane. The membrane was then blocked with 3\% BSA for $1.5 \mathrm{~h}$, followed by overnight incubation at $4^{\circ} \mathrm{C}$ in the primary antibody. After the membrane was washed, a HRP-conjugated secondary antibody was added and incubated for 1.5 h. The bands were detected by an ECL kit and quantified by Quantity One software.

\section{Immunohistochemistry}

Frozen sections were washed with PBS for $5 \mathrm{~min}$. The primary antibodies we used were anti-mouse p-PKC $\delta$ (1:200 dilution; Abcam), anti-p-SrcTyr416 (1:200; Abcam). Primary antibodies were incubated with tissue sections for $60 \mathrm{~min}$ at room temperature. Primary antibodies were diluted in solution $(1 \%$ bovine serum albumin in $0.01 \mathrm{M}$ TBS, $\mathrm{pH} 7.2)$. Then, slides were washed with PBS thrice for 5-min each, followed by incubation with biotin-conjugated corresponding secondary antibodies for $20 \mathrm{~min}$ at $37^{\circ} \mathrm{C}$. Then, slides were washed with PBS thrice for 5 -min each to remove unbound antibody. Samples were incubated with streptococcal avidin-biotin complex reagent for $20 \mathrm{~min}$ at $37^{\circ} \mathrm{C}$. 3,3'-diaminobenzidine was used for color development (Beyotime, Jiangsu, China). Sections were re-stained with hematoxylin. After dehydration and sealing, sections were observed under a microscope.

\section{Statistical analysis}

GraphPad Prism software (Version 4.0, Graph-
Pad Software Inc., San Diego, CA) was used to perform the data analysis. Data are expressed as the mean $\pm S D$. Statistical significance between different groups was calculated by a one-way ANOVA where appropriate or a Student's two tailed t-test; $P$ values below 0.05 were considered statistically significant.

\section{Results}

\section{Effect of $\mathrm{Cl}$ on endothelial monolayer permeability and ultrastructural characterist- ics of TJs in vitro}

The structure of $\mathrm{C} 1$ is shown in Fig. 1A. The effects of TNF-a or C1 on HUVEC monolayer permeability were examined by detecting the TEER of the endothelial cell monolayer and performing transwell Na-F assays. C1 at concentrations of 0.01 , 0.1 , and $1 \mu \mathrm{M}$ was applied for $1 \mathrm{~h}$, followed by TNF- $\alpha$ stimulation for $4 \mathrm{~h}$. TNF-a-induced barrier disruption resulted in a sharp decrease in TEER and an increase in the Na-F permeability coefficient. However, C1 enhanced TEER and decreased the Na-F permeability coefficient (Fig. 1B \& C). An in vitro co-culture model was established by using HUVECs-A549 cells, and the anti-metastasis effect of $\mathrm{C} 1$ was assessed. As shown in Fig. 1D, in a TNF-a-stimulated HUVEC inflammation model, transendothelial migration of A549 cells increased significantly, while $1 \mu \mathrm{M} \mathrm{C} 1$ inhibited the migration of A549 cells.
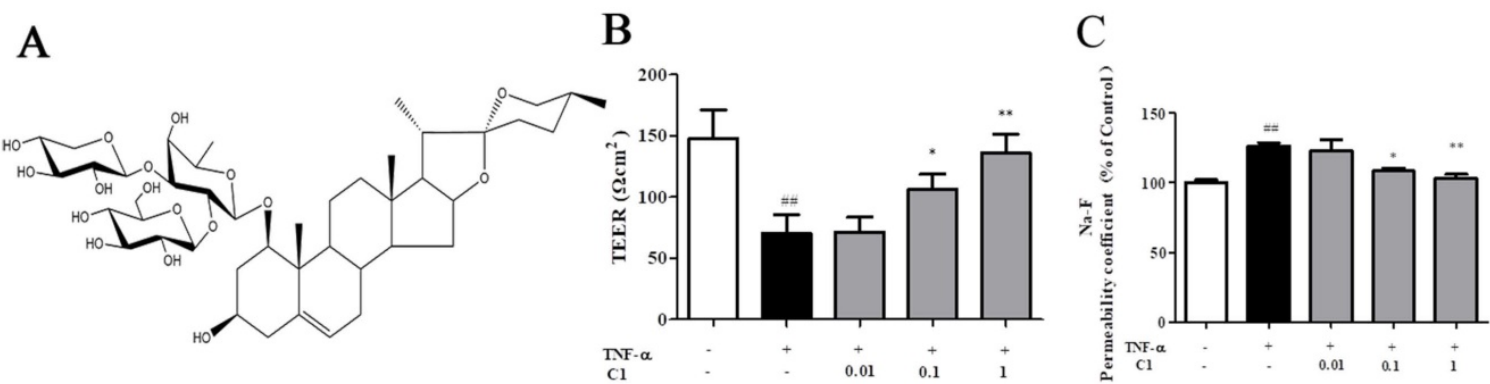

$\mathrm{D}$ Control

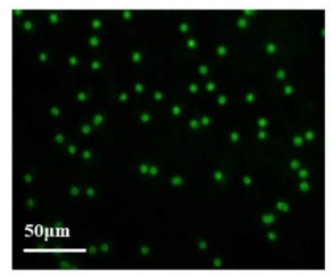

TNF- $\alpha$ (10ng/ml)

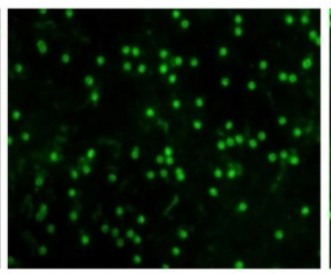

B

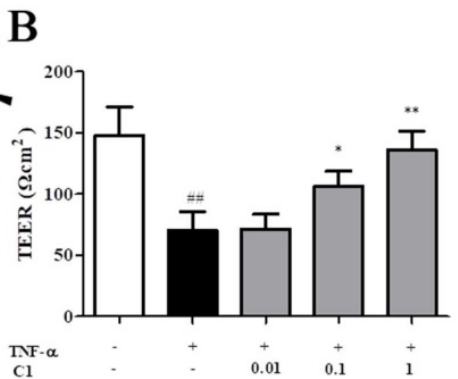

C1

$(1 \mu \mathrm{M})$

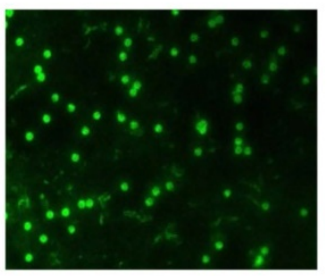

$\mathrm{E}$

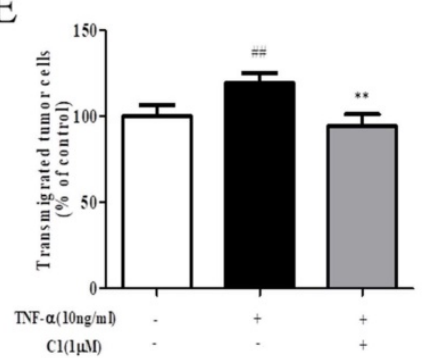

Figure 1. Cl ameliorated TNF- $\alpha$-induced endothelial hyperpermeability and transendothelial migration of A549 cells. EC permeability was measured using a Millicell-ERS voltohmmeter. HUVECs were pretreated with various concentrations of $\mathrm{Cl}(0.01,0.1$ and $1 \mu \mathrm{M})$ for $1 \mathrm{~h}$ followed by TNF- $\alpha(10 \mathrm{ng} / \mathrm{mL})$ stimulation for $4 \mathrm{~h}$. (A) The chemical structure of $\mathrm{Cl}$. (B) The transendothelial permeability was assessed by TEER. (C) The transendothelial permeability was assessed using the paracellular transport marker (Na-F) permeability coefficient, which was measured using a fluorescence multiwall plate reader [Ex $(\lambda) 485 \mathrm{~nm}$; Em $(\lambda) 530 \mathrm{~nm}$ ]. (D)\&(E) HUVECs grown to confluence on transwell inserts were activated or not (control) with TNF-a (10 ng/mL). After $4 \mathrm{~h}$, calcein-AM-labeled A549 cells were seeded onto the inserts. After $48 \mathrm{~h}$, melanoma cell migration across HUVEC monolayers was analyzed. Bar $=50 \mu \mathrm{m}$. The data represent the mean $\pm \mathrm{SD}$ from three experiments. \#P<0.01 vs. the control group; $* P<0.05$, $* * P<0.01$ vs. the TNF- $\alpha$ group. 


\section{Effect of $\mathrm{Cl}$ on lung cancer in nude mice}

After 4 weeks of inoculation of lung cancer cells in the caudal vein, no death was observed in the model nude mice. After the model was established, the fixed pulmonary tissue images and hematoxylin and eosin staining results, as shown in Fig. 2A, demonstrated that the sham group of nude mice had smooth lung tissues, no tumor nodules, normal tissue distribution, and no cell aggregation; mice in the model group shown multiple visible lung tumor nodules with increased sizes and tissue metastasis, and the cell structures were round or oval, with large nuclei, deep staining, and a nucleocytoplasmic ratio consistent with the pathological features of adenocarcinoma. In contrast, $\mathrm{C} 1$ at a dose of $10 \mathrm{~g} / 0.1$ $\mathrm{mL}$ resulted in no visible lung tumor nodules and significantly decreased lung metastases, with significant inhibition of lung cancer metastasis. The positive control group (TPT treated group) shown similar results.

Next, we demonstrated the in vitro anti-lung cancer effects of $\mathrm{C} 1$ on endothelial cell migration by inhibiting TNF-a-induced HUVEC damage in the endothelial barrier. We also confirmed these effects in an experimental model of lung cancer metastasis and on pulmonary vascular tumor cells from the circulation into lung tissues, which act as a barrier.
Therefore, we used Evans blue leakage to detect the pulmonary vascular permeability in nude mice treated with $\mathrm{C} 1$ to assess experimental metastasis of lung cancer; the experimental results are shown in Fig. 2C. The model group mice shown significantly increased pulmonary vascular leakage of Evans blue, which was approximately 2-3 times higher than that of the normal group, while $\mathrm{C} 1$ at a dose of $10 \mathrm{~g} / 0.1$ $\mathrm{mL}$ significantly inhibited pulmonary vascular leakage of Evans blue and had a protective effect on vascular integrity; the positive control group shown similar results.

Finally, an experimental lung cancer metastasis model was used, which was not the same as the TNF-a-induced HUVEC in vitro model. The occurrence and development of tumors are closely related to their secretion of various inflammatory factors. Therefore, the level of plasma TNF-a in nude mice was detected by ELISA kits, and the results are shown in Fig. 2D. The plasma level of TNF-a in nude mice increased significantly compared with that in the blank control group, while $\mathrm{C} 1$ inhibited the increase of TNF-a level in nude mice and regulated the level of inflammation in the tumor-bearing mice. The positive control group also had a significant increase in the level of TNF-a.
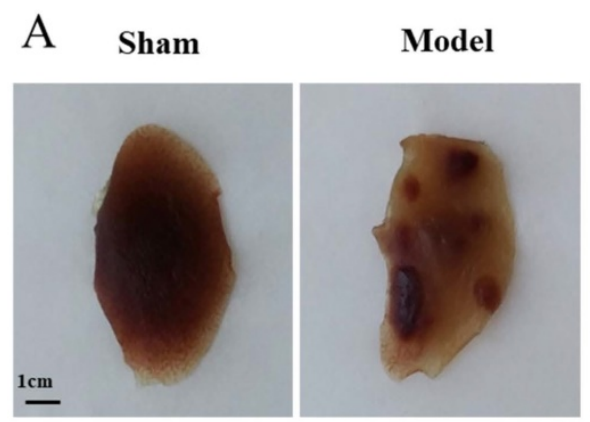

B Sham

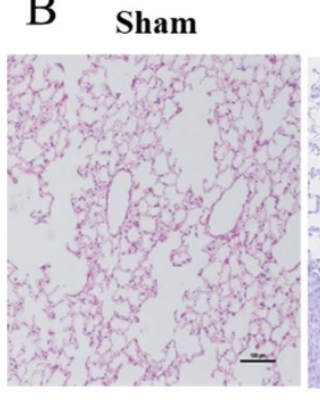

Model
C1

(4mg/kg)

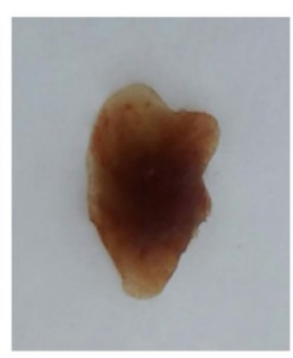
$\mathrm{C1}$
$(4 \mathrm{mg} / \mathrm{kg})$

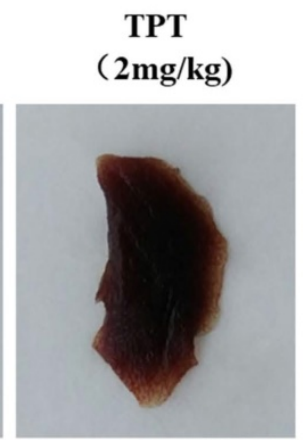

TPT

Model (2mg/kg) (4mg/k)

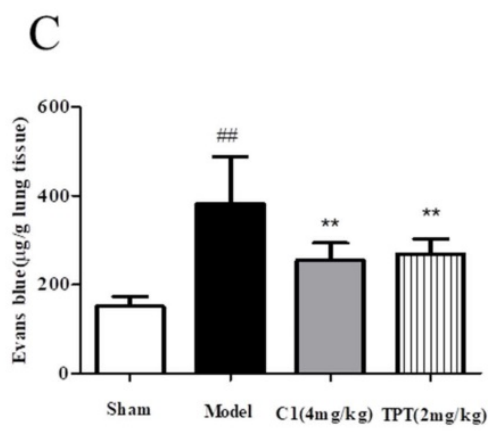

D

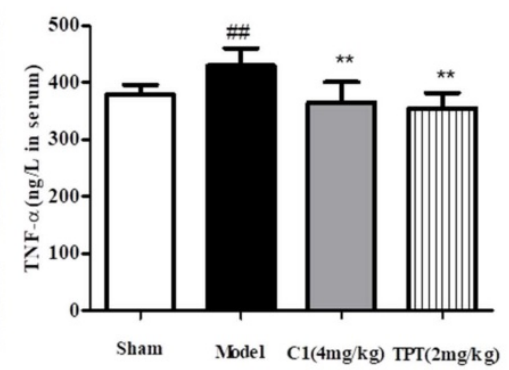

Figure 2. Cl suppressed lung cancer in the nude mouse model of experimental pulmonary adenocarcinoma metastasis. (A) \& (B) At autopsy, the lungs were removed and fixed in $4 \%$ formaldehyde before they were embedded in paraffin, and then, sections were photographed and stained with hematoxylin and eosin. (C) Lung vascular permeability was detected using Evans blue leakage after the model was established, and the degree of vascular permeability was reflected by OD values of Evans blue. (D) Plasma TNF- $\alpha$ levels of each group were detected with an ELISA kit after model establishment. ${ }^{\prime} P<0.01$ vs. Sham group; ${ }^{* *} P<0.01$ vs. Model group. 


\section{Effect of $\mathrm{Cl}$ on the organization and expression of ZO- 1 in vitro and in vivo}

Downregulation of the TJ protein ZO-1 may be critical for disruption of the endothelial barrier [26]. This protein shown discrete localization in response to TNF-a treatment; however, ZO-1 in HUVECs treated with $\mathrm{C} 1$ was intact, in contrast to that in the model group. HUVECs were exposed to TNF-a and assessed for ZO-1 expression by Western blot analyses (Fig. 3A). The ZO-1 protein maintains the structural integrity of TJs in endothelial cells. Using immunofluorescence, we identified the localization of ZO-1 at the endothelial cell contacts of confluent cells (Fig. 3B). As shown in Fig. 3C, mice were pretreated with $\mathrm{C} 1(4.0 \mathrm{mg} / \mathrm{kg})$ for $1 \mathrm{~h}$ and then administered TNF-a $(100 \mu \mathrm{g} / \mathrm{kg})$ for $4 \mathrm{~h}$. The ZO-1 protein expression was significantly increased compared to that of the model group. Immunostaining of ZO-1 in the mouse aortic endothelium shown that TNF- $\alpha$ abolished the endothelial junction proteins at the cellcell contact zones between adjacent cells. C1 (4.0 $\mathrm{mg} / \mathrm{kg}$ ) inhibited ZO-1 disassembly (Fig. 3C).
First, the distribution and expression of ZO-1 in pulmonary vascular endothelial cells were examined by immunofluorescence. Second, Western blotting was used to detect ZO-1 protein expression in lung tissues, and the results are shown in Fig. 3. Immunofluorescence results demonstrated that ZO-1 expression on the endothelial cells of the blank group was continuous, while the ZO-1 on the endothelial cells in the model group appeared discontinuous and filamentous. There was a deletion or breakpoint in the middle of the protein expression. Treatment with 10 $\mathrm{g} / 0.1 \mathrm{~mL} \mathrm{C} 1$ inhibited the rupture of ZO-1 and maintained a continuous linear shape of the protein expression. Western blotting results shown that $\mathrm{ZO}-1$ expression in the lung tissue of nude mice was significantly decreased by tumor inoculation, while C1 significantly inhibited ZO-1 degradation and maintained its protein expression, which was consistent with the immunofluorescence results. The positive control group also shown the same results (Fig. 3C \& D).
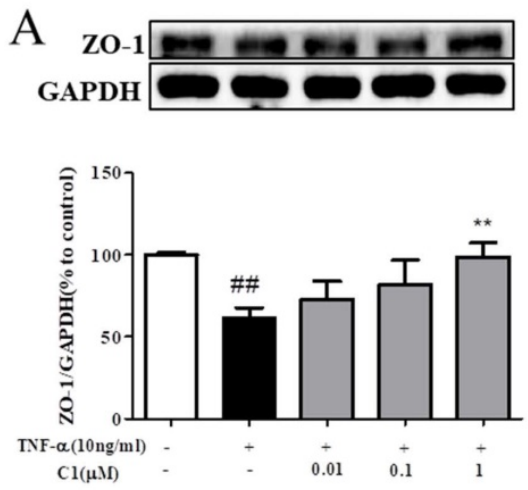

$\mathrm{C}$

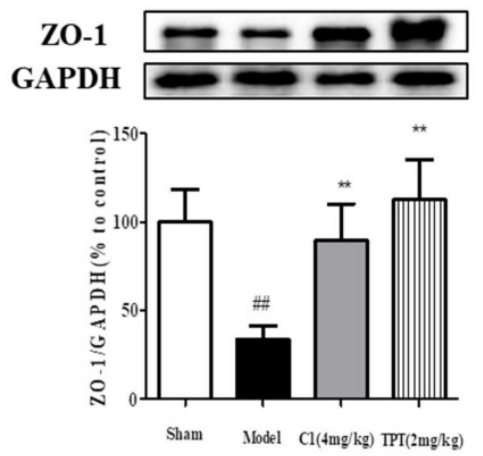

$\mathrm{B}$

ZO-1

DAPI

Merge

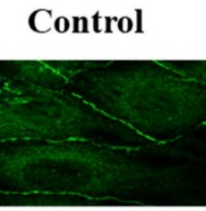

TNF- $\alpha$ (10ng/ml)

C1

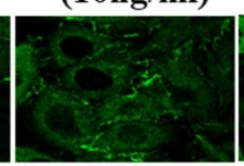

$(1 \mu \mathrm{M})$
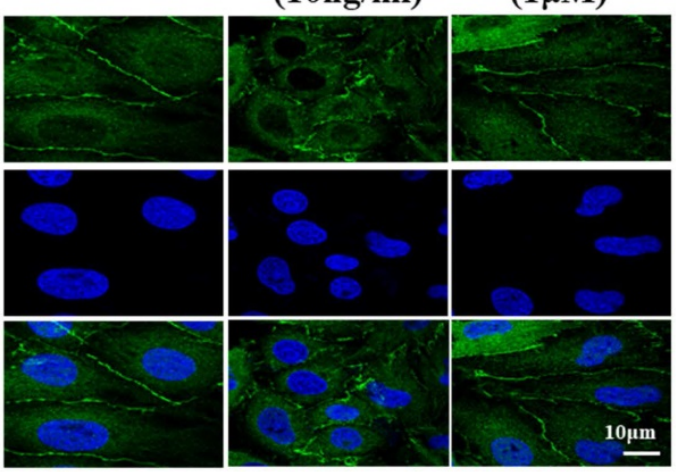

C1

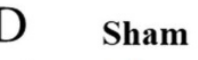

CD31

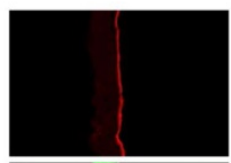

Model

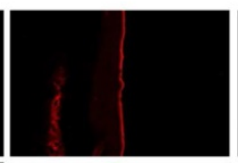

$(4 \mathrm{mg} / \mathrm{kg})$

TPT

ZO-1
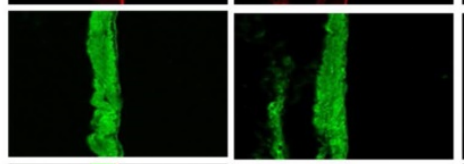

Merge
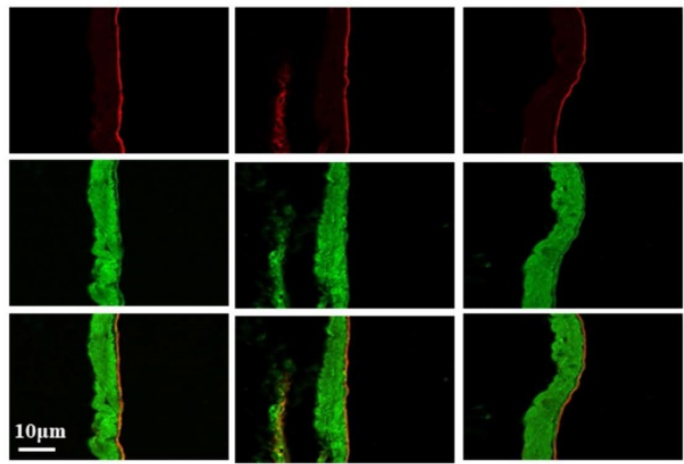

(2mg/kg)

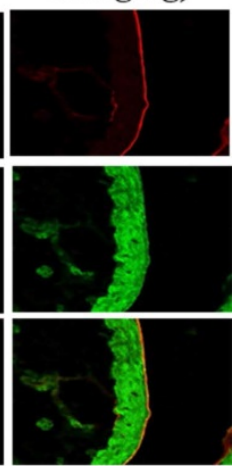

Figure 3. $\mathrm{Cl}$ inhibited degradation and rearrangement of the tight junction protein ZO- 1 in vitro and in vivo. (A) Western blotting analysis revealed that $\mathrm{Cl}$ at $1 \mu \mathrm{M}$ inhibited degradation of the tight junction protein ZO-1 in HUVECs. (B) Immunofluorescence analysis shown consistent ZO-1 localization in HUVECs. The data represent the mean $\pm S D$ from three experiments. $P<0.01$ vs. Control group; **P<0.01 vs. the TNF- $\alpha$ group. (C) The expression of $Z O-1$ in mouse lung tissue was detected by Western blotting. (D) The distribution of ZO-1 in mouse pulmonary vessel was measured by immunohistochemistry. The results were obtained from three independent experiments and are expressed as the mean \pm SD. Representative confocal microscopy images of immunostaining of ZO- 1 in the mouse pulmonary vessel. ${ }^{\#} P<0.01$ vs. Sham group; ${ }^{* *} P<0.01$ vs. Model group. 


\section{The PKC $\delta$ inhibitor rotterlin suppresses the metastasis of A549 cells}

First, the effects of the PKC $\delta$ inhibitor rotterlin $(0.01,0.1,1 \mathrm{M})$ on TNF-a-induced endothelial permeability were assessed by TEER and Na-F assays, and the results are shown in Fig. 4A\&B. TNF-a stimulation increased endothelial permeability, TEER decreased significantly, and Na-F leakage increased significantly, while rotterlin treatment significantly inhibited endothelial permeability at a concentration of $0.1 \mu \mathrm{M}$. Second, we studied the effects of rotterlin $(0.01,0.1,1 \mu \mathrm{M})$ on the TNF- $\alpha$-induced TJ protein ZO-1 by Western blotting analysis. The results shown that rotterlin could inhibit the TNF-a-induced degradation of ZO-1 in a concentration-dependent manner. Meanwhile, the effect of the PKC $\delta$ agonist TNF-a on ZO-1 was investigated. The results shown that ZO-1 degradation could be induced by TNF-a alone, and its function was similar to that of TNF-a, indicating that PKC $\delta$ plays an important role in regulating endothelial permeability.

As shown in Fig. 4D\&E, after TNF-a stimulation for $4 \mathrm{~h}$, the endothelial cell permeability increased, and the transendothelial migration of tumor cells of A549 cells increased significantly. The PKC $\delta$ inhibitor rotterlin $(1 \mu \mathrm{M})$ could inhibit metastasis, and the effect was significant.

\section{Effect of $\mathbf{C l}$ on TNF- $\alpha$-induced Src activity}

The results, as indicated by Fig. 5A \& B, shown that stimulation with TNF- $\alpha$ activated the intracellular Src protein kinase via phosphorylation of Src and mediated the downstream reaction. Pretreatment with the PKC $\delta$ inhibitor rotterlin $(0.01,0.1,1 \mu \mathrm{M})$ inhibited Src protein kinase activation and blocked the downstream reaction, and the inhibitory effect of rotterlin $(1 \mu \mathrm{M})$ was comparable to that of the Src protein kinase inhibitor PP1/PP2. Activation of Src protein kinase is regulated by the Tyr416 and Tyr527 residues. The Tyr527 localization of inhibitory Src kinase is mediated by self-phosphorylation, while Tyr416 dephosphorylation and activated Src kinase show the opposite results [27]. Analysis of the phosphorylation level of Src kinase at these sites can fully explain the activation state.

As indicated by Fig. 5C, D \& E, HUVECs were stimulated by TNF-a, and both PKC $\delta$ and Src were activated by phosphorylation and mediated the downstream reaction. Pretreatment with $\mathrm{C} 1(0.01,0.1$, $1 \mu \mathrm{M})$ inhibited the activation of PKC $\delta$ and Src protein kinase and then blocked the downstream reaction.
A

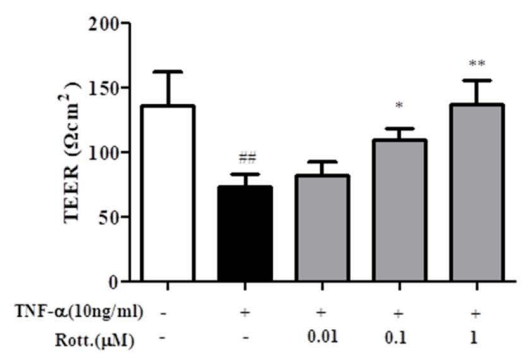

B

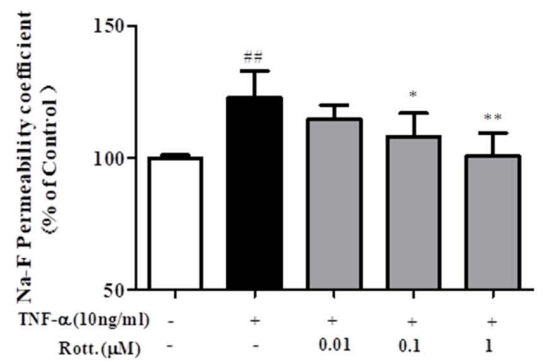

C zo-1 GAPDH

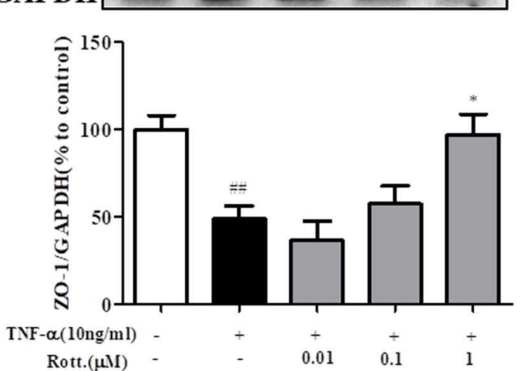

D

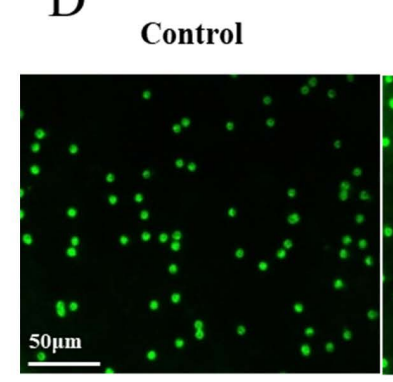

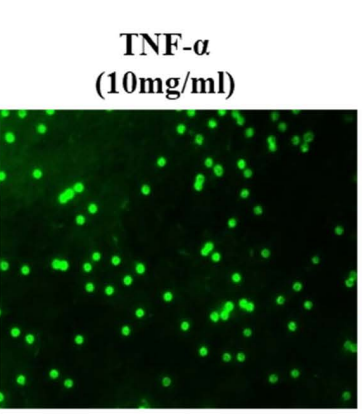

Rotterlin $(1 \mu \mathrm{M})$

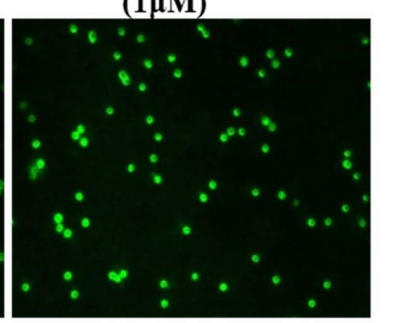

$\mathrm{E}$

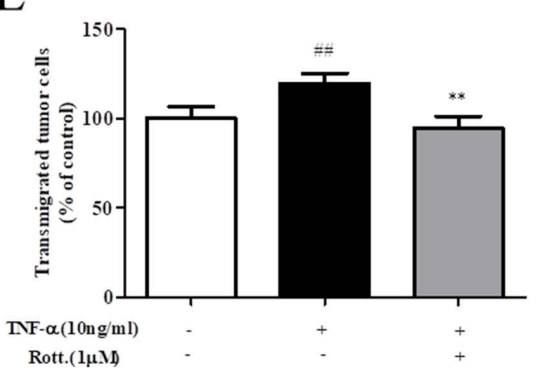

Figure 4. The PKCठ inhibitor rotterlin inhibited TNF- $\alpha$-induced endothelial hyperpermeability and transendothelial migration of A549 cells. HUVECs were pretreated with rotterlin $(0.01,0.1,1 \mu M)$ and then exposed to TNF- $\alpha$ for $4 \mathbf{h}$. (A)\&(B) Effect of rotterlin on TNF-a-induced HUVEC permeability. TEER and Na-F permeability coefficient were determined using a fluorescence multiwall plate reader [Ex $(\lambda) 485 \mathrm{~nm}$; Em $(\lambda) 530 \mathrm{~nm}]$. (C) Effect of rotterlin on ZO-1 expression in TNF-a-induced HUVECs. Western blotting analysis revealed that Rotterlin could suppress degradation of ZO-1 in HUVECs induced by TNF- $\alpha$ (10 ng/mL). (D)\&(E) HUVECs grown to confluence on transwell inserts were activated or not (control) with TNF- $\alpha$ (10 ng/mL). After $4 \mathrm{~h}$, calcein-AM-labeled A549 cells were seeded onto the inserts. After $48 \mathrm{~h}$, melanoma cell migration across HUVEC monolayers was analyzed. Bar graphs show the mean \pm s.e.m. ( $n=6$ random fields from a duplicate determination). \#\#P<0.01 vs. control group, $* * P<0.01$ vs. model group treated with TNF- $\alpha$ alone. 

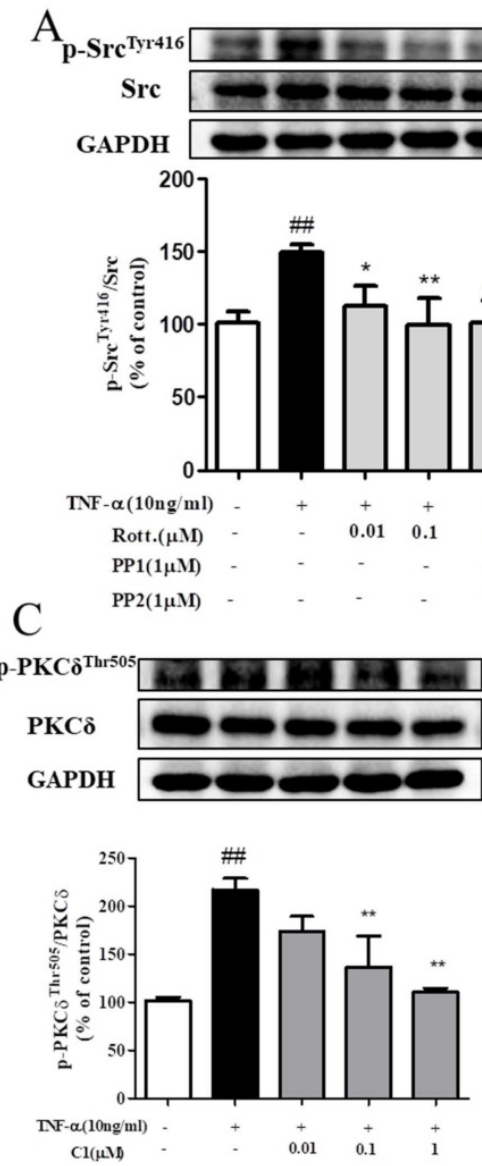

D
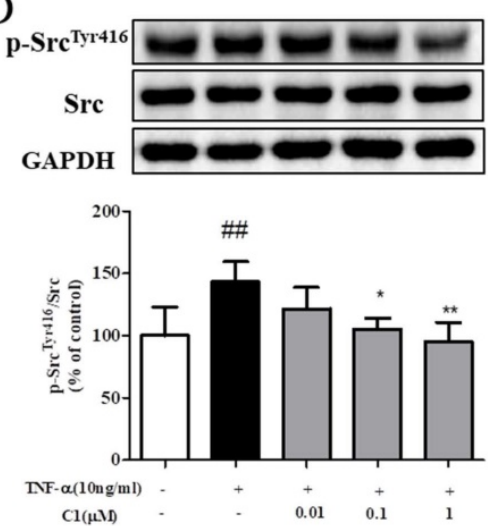

$\mathrm{B}$

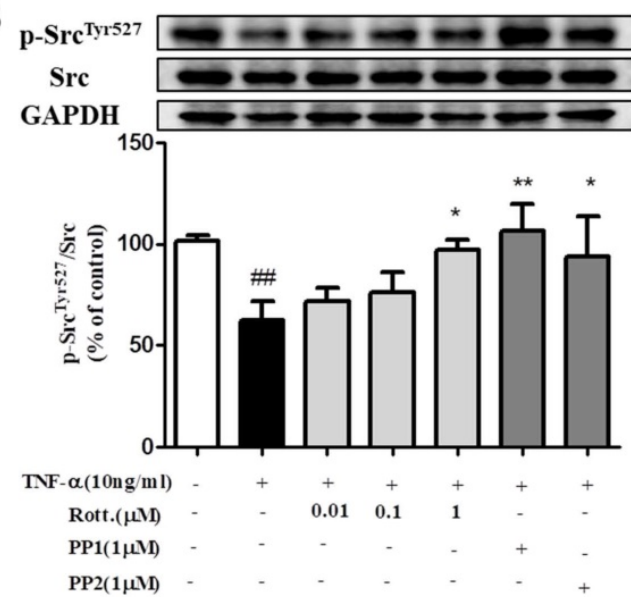

$\mathrm{E}$
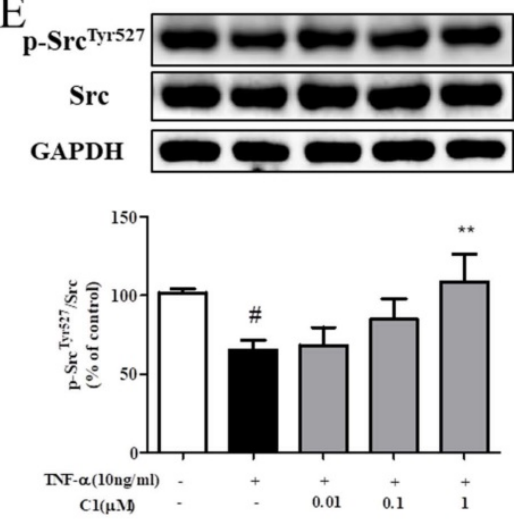

Figure 5. C1 inhibited activation of protein kinase PKC $\delta$ and Src in HUVECs induced by TNF- $\alpha$. (A)\&(B) HUVECs pretreated with rotterlin ( $0.01,0.1$, $1 \mu \mathrm{M}$ ) or PP1/PP2 followed by TNF- $\alpha$ for $4 \mathrm{~h}$. Western blotting analysis revealed that rotterlin $(1 \mu \mathrm{M})$ significantly inhibited activation of Src protein kinase. (C) Effect of $\mathrm{Cl}$ on activation of PKC $\delta$ in HUVECs after TNF- $\alpha$ stimulation for $15 \mathrm{~min}$. (D)\&(E) Effect of Cl on activation of Src in HUVECs stimulated by TNF- $\alpha$ for $4 \mathrm{~h}$. The data represent the mean \pm SD from three experiments. $\# P<0.05$, \# $P<0.01$ vs. Control group; ${ }^{*} P<0.05, * * P<0.01$ vs. the TNF- $\alpha$ group.

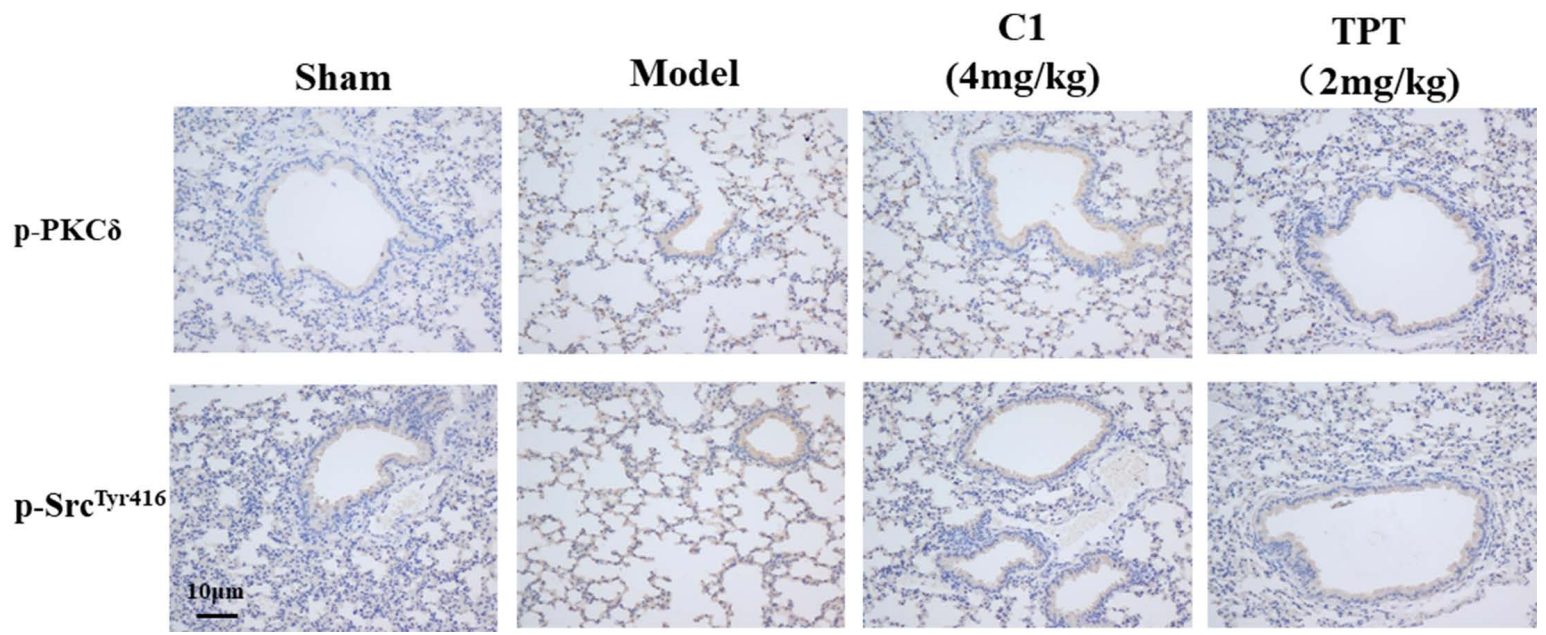

Figure 6. $\mathrm{Cl}$ suppress the expression of p-PKC $\mathrm{P}$ and $\mathrm{p}$-Src in the nude mouse model of experimental pulmonary adenocarcinoma metastasis. Lung tissue frozen sections were washed with PBS for 5 min. The primary antibodies anti-mouse p-PKC $\delta$ (1:200 dilution; Abcam), anti-p-SrcTyr416 (1:200; Abcam) were incubated with tissue sections for $60 \mathrm{~min}$ at room temperature. Sections were re-stained with hematoxylin. After dehydration and sealing, sections were observed under a microscope.

\section{Effect of $\mathrm{Cl}$ on the expression of p-PKCס and p-Src in nude mice}

As shown in Fig. 6, the p-PKC $\delta$ and p-Src protein expression was increased in the model group detected by immunohistochemistry. With the treated by $\mathrm{C} 1(4 \mathrm{mg} / \mathrm{kg})$, the expression of p-PKC $\delta$ and p-Src reduced in the lung silice(Fig $6 \mathrm{~A} \& \mathrm{~B}$ ). The result shown that $\mathrm{C} 1$ could inhibit the expression of $\mathrm{p}-\mathrm{PKC} \delta$ and $\mathrm{p}$-Src in the model. 


\section{Discussion}

In this study, we investigated the regulatory effects of $\mathrm{C} 1$ on lung cancer and its vascular endothelial barrier function and explored the mechanisms of $\mathrm{C} 1$. C1 can inhibit lung cancer in vivo, regulate the level of plasma inflammation in tumor-bearing mice, and protect the pulmonary vascular barrier against injury induced by cancer. We investigated the expression and distribution of the TJ index protein ZO-1 in mouse vascular endothelium and HUVECs and found that $\mathrm{C} 1$ could inhibit the degradation and breakage of the ZO-1 protein. Related signaling experiments confirmed that $\mathrm{C} 1$ can inhibit TNF- $\mathrm{a}$ and activation of PKC $\delta$ and Src kinase, thereby reducing endothelial permeability and improving barrier function.

Tumor development is closely related to inflammation. The inflammatory microenvironment of the primary site of the tumor promotes growth, development and metastasis [28]. Research has shown that the TNF-a level in cancer patients and other patients is closely related to prognosis $[29,30]$. High levels of inflammation in tumor-bearing mice can increase vascular permeability, and tumor tissues also secrete many factors to induce the destruction of vascular endothelial integrity [31,32]. Along with the deterioration of other tissues during the aging process, immune system function declines as well [33]. Hence, immune surveillance is a key factor in preventing cancer progression, and immunosenescence is another important factor that links tumorigenesis and aging [34]. Increased permeability results in leakage of the vascular endothelial cells from the circulation into lung tissues and creates favorable conditions for tumors, while C1 can significantly inhibit the increase in vascular permeability, protect vascular integrity, block tumor cell exudation, and inhibit the metastasis of tumor cells (see Fig. 1). The in vitro experiments in this study examined the effects of the inflammatory factor TNF- $\alpha$; thus, in nude mice in vivo, plasma TNF- $\alpha$ levels were detected. The results shown that plasma TNF-a increased significantly in the nude model mice, while $\mathrm{C} 1$ significantly reduced the increase in plasma TNF- $a$ levels caused by tumor inoculation, and inflammation significantly improved the tumor microenvironment (see Fig. 2D).

Lung cancer is the most frequent cause of cancer-related death worldwide and has a high rate in many elderly patients [35]. In cancer metastasis, vascular endothelial cells form the major barrier of tumor cells moving from the tissue to the circulatory system to the tissue [36]. The increase in vascular endothelial cell permeability provides favorable conditions for the metastasis of tumor cells, and the close connection of endothelial cells is an important basis for the vascular barrier. TJs are important factors in endothelial integrity. TJs can effectively block cell gaps and form between cell barriers [37]. Clinical studies shown that the transcription level of $\mathrm{TJ}$ proteins in patients with NSCLC was significantly decreased, and their expression levels were closely related to the prognosis of NSCLC patients. Therefore, by protecting endothelial cell integrity, maintaining TJs of endothelial cells, and inhibiting invasion and metastasis of lung cancer cells, effective intervention in the early stage of lung cancer occurrence and metastasis may be an important direction for future research and development of anti-lung cancer metastasis drugs [38]. The determination of transendothelial resistance and the determination of the change in cell culture chamber material leakage rate are used to assess cell permeability; by using a TEER tracer to measure the transfer current for solute ion strength, permeability changes can be recorded in real time. Na-F assays of monolayer cells and macromolecules were also performed [39]. In this study, TEER and Na-F were used to observe the effect of $\mathrm{C} 1$ on HUVEC permeability induced by TNF- $\mathrm{a}$, and the HUVEC permeability was examined in different assays. The results were reasonable and consistent (shown in Fig. 1). Meanwhile, we used the nude mouse model of experimental pulmonary adenocarcinoma metastasis to study the anti-tumor effect of $\mathrm{C} 1$. The results shown that there were significantly fewer tumor nodules in the $\mathrm{C} 1$ and TPT groups than the model group, which demonstrated that $\mathrm{C} 1$ can inhibit the lung tumors in vivo (see Fig. 2).

Intercellular TJs are a transmembrane protein complex composed of transmembrane proteins (Occludin, Claudins polygene family, JAM) and cytoplasmic proteins (ZO-1 and others) [40]. The ZO-1 protein is the most important protein in the cytoplasm, constitutes an important component of the TJs, and connects to the main cell body to act as intermediate transmembrane protein and part of the actin cytoskeleton. Functional and structural changes can cause dissociation of TJs and increased intercellular space, thereby increasing the vascular permeability [12]. The expression and structural changes of ZO-1 involve a series of complex intracellular signal transduction pathways, including tyrosine kinase Src, protein kinase $\mathrm{C}, \mathrm{Ca}^{2+}, \mathrm{G}$ protein, cAMP and other signaling pathways [41]. When endothelial cells are stimulated by TNF- $\alpha$, the permeability of endothelial cells increases and the ZO-1 protein is degraded. Some studies have shown that Src kinase activation is involved in the formation of TNF-a-induced vascular inflammation and plays an important role in the endothelial cell barrier 
function [42]. Thus, the TJ protein ZO-1 was significantly degraded after TNF-a stimulation, and pretreatment with $\mathrm{C} 1$ could significantly inhibit the degradation of ZO-1 in a concentration-dependent manner (see Fig. 3A \& B). Compared with the control group, the model group shown decreased ZO-1 expression. $\mathrm{C} 1$ and TPT administration could significantly improve pulmonary vascular permeability and increase the expression of $\mathrm{ZO}-1$ protein, indicating that the anti-tumor effect of $\mathrm{C} 1$ was related to its protection of pulmonary vascular integrity (see Fig. 3C \& D).

We also found that the positive control drug TPT significantly regulates the expression of $\mathrm{ZO}-1$, and this regulation is related to the inhibition of PKC $\delta$ activation (see Fig. 3C \& D). TPT has a slight clinical effect in the treatment of small cell lung cancer. This drug binds to the topoisomerase I-DNA complex, preventing the repair of single-stranded DNA after reversible disruption induced by topoisomerase I, resulting in cell death $[43,44]$. This study found that TPT inhibited the destruction of the lung vascular barrier induced by cancer and provides a new clue for its mechanism.

PKC $\delta$ can be activated through a Src-dependent mechanism. Src regulation of PKC $\delta$ was also reported [21]. However, PKC $\delta$ has little effect on Src, and this has not been reported in vascular endothelial cells. To further elucidate the possible molecular mechanism of $\mathrm{C} 1$ in regulating TNF-a-induced barrier function of HUVECs, we investigated the effect of the PKC $\delta$ inhibitor rottlerin on TNF-a-induced endothelial permeability, TJ protein ZO-1 degradation, A549 transendothelial migration and activation of Src kinase. TEER, Na-F leakage, HUVECs-A549 cell co-culture and Western blotting results shown that rottlerin can significantly inhibit TNF-a-induced HUVEC permeability, A549 transendothelial migration, and activation of Src kinase in a concentration-dependent manner (see Fig. 4).

Clinical studies have shown that in NSCLC tumor tissues, the protein expression of the kinase PKC $\delta$ is increased, and rottlerin can effectively induce apoptosis of tumor cells [18]. Moreover, with the inflammatory factor TNF- $\delta$ or IL- $1 \beta$, PKC $\beta$ participates in the increase of endothelial cell permeability and the degradation of the closely related connexin ZO-1 $[19,45,46]$. Therefore, interfering with protein kinase PKC $\delta$ and Src, regulating the close connection of endothelial cells and protecting endothelial barrier function may be an effective strategy to inhibit tumor metastasis. Other studies have shown that PKCס is involved in inflammatory factor-mediated endothelial inflammatory models [19]. In addition, C1 (0.01, 0.1, 1 $\mu \mathrm{M})$ significantly inhibited TNF-a-induced phos- phorylation of the PKC $\delta$ and Src kinase proteins (see Fig. 5).

In traditional Chinese medicine, "Ophiopogon japonicus" was first used in Shennong Ben Cao Jing. It is commonly used in traditional Chinese medicine. Its medicinal properties are sweet, bitter and cold. This medicine is believed to moisten the lungs, promote fluid, nourish the yin and clear away heat. Modern pharmacological research has shown that O. japonicus has anti-inflammatory and anti-tumor effects and protects against endothelial damage [47-49]. The main chemical components of Ophiopogon are steroid saponins, isoflavones, phenolic acids, polysaccharides and others. A previous study by our group shown that the saponins from Ruscogin were the main active components of anti-inflammatory and anti-tumor drugs. Ophiopogonin DT-13 was reported to be involved in regulating TNF- $\alpha$-induced endothelial inflammation, regulating the activity of non-muscle myosin IIA under hypoxia, and inhibiting the metastasis of 95D cells in lung cancer [23,50,51]. However, whether other saponins in O. japonicus can exhibit stronger anti-inflammatory effects and protect endothelial integrity and tumor metastasis activity is not clear. Whether they can play a protective role by regulating the activity of $\mathrm{PKC} \delta$ and Src is also unknown. In this study, we used a nude mouse model of experimental pulmonary adenocarcinoma metastasis to study the anti-metastasis effects of $\mathrm{C} 1$, a new chemical compound isolated from $O$. japonicus. The results shown that the tumor nodules in the $\mathrm{C} 1$ and TPT groups were significantly fewer than those in the model group, which demonstrated that $\mathrm{C} 1$ can inhibit the metastasis of lung tumors in vivo. At the same time, the effects of $\mathrm{C} 1$ on pulmonary vascular permeability and endothelial TJs were investigated. Compared with the control group, the model group had significantly higher pulmonary vascular permeability and significantly decreased ZO-1 expression. C1 and TPT administration could significantly improve pulmonary vascular permeability and increase the expression of ZO-1 protein, indicating that the anti-metastasis effect of $\mathrm{C} 1$ was related to its protection of pulmonary vascular integrity. In this study, we investigated the effect of $\mathrm{C} 1$ on the TJ proteins of HUVECs using immunohistochemistry and Western blotting. The results shown that the TJ protein ZO-1 was significantly degraded after TNF-a stimulation, and pretreatment with $\mathrm{C} 1$ could significantly inhibit the degradation of ZO-1 in a concentration-dependent manner.

We found that $\mathrm{C} 1$ had an obvious effect on TNF-a-induced endothelial cell barrier damage and verified its anti-tumor effect on lung cancer in vitro and in vivo. We also demonstrated that the inhibition 
of PKC $\delta$ and Src is one important mechanism underlying the protective effects of $\mathrm{C} 1$ on vascular endothelial integrity, which may explain other activities of $O$. japonicus.

Therefore, we used vascular endothelial cells to assess the changes in endothelial permeability and TJ function and structure. Our findings lay the foundation for the discovery of the new drugs based on Ophiopogon saponins. Meanwhile, our results provide experimental evidence demonstrating the role of the vascular endothelium in tumor metastasis and may contribute to the development of anti-tumor metastasis drugs from effective components of traditional Chinese medicine. Therefore, starting from traditional Chinese medicine theory and using modern medical research methods, researchers should search for highly active drugs to inhibit metastasis of lung cancer from O. japonicus, which may contribute to the research and treatment of tumors and the rational application of traditional Chinese medicine. Despite the above research results, there are still some limitations of this study. Further research is needed to determine whether the regulation of endothelial function by ophiopogonin A1 and C1 plays a direct role in PKC delta or Src. Are there other key proteins upstream? In a whole animal model, how does C1 regulate the level of plasma inflammation in tumorbearing mice? Is there a direct correlation between the protective effect of O. japonicus saponins and the level of plasma inflammation? The above problems were studied by RNA interference and gene knockout to help elucidate the molecular mechanism of $O$. japonicus saponins $\mathrm{A} 1$ and $\mathrm{C} 1$ in the prevention and treatment of lung cancer metastasis and lay the foundation for its clinical development.

\section{Abbreviations}

BSA: Bovine serum albumin; EBA: Evan's blue-labelled albumin; ECL: Enhanced chemiluminescence; FBS: Fetal bovine serum; HRP: Horse radish peroxidase; HUVECs: Human umbilical vein endothelial cells; Na-F: Fluorescein sodium; NSCLC: Non-small cell lung cancer; PBS: Phosphate buffer salts; PKC: Protein kinase C; PVDF: Polyvinylidene fluoride; SDS: Sodium dodecylsulfate; TEER: Transendothelial electrical resistant; TJs: Tight junctions; TNF-a: Tumor necrosis factor-a; TPT: Topotecan hydrochloride; Tris: hydroxymethyl aminomethane.

\section{Supplementary Material}

Supplementary table S1.

http://www.ijbs.com/v16p0396s1.pdf

\section{Acknowledgements}

\section{Authors and Contributors}

Yuanyuan Zhang, Junping Kou and Boyang Yu designed experiments. Yuanyuan Zhang and Yazheng Zhao performed experiments. Yan $\mathrm{Wu}$ and Jin Qi isolated the C1 from Liriope muscari (Decne.) L.H. Bailey. Yuanyuan Zhang wrote the manuscript. Fang Li and Junping Kou polished the language. All authors contributed toward editing the manuscript.

\section{Funding}

This study was supported by the National Natural Science Foundation of China (No.81503295), "Double First-Class" University project (CPU2018GF07), the Fundamental Research Funds for the Central Universities (2632019ZD17).

\section{Availability of data and material}

The datasets used and/or analyzed during the current study are available from the corresponding author on reasonable request.

\section{Competing Interests}

The authors have declared that no competing interest exists.

\section{References}

1. Hirsch F.R., Scagliotti G.V., Mulshine J.L., et al. Lung cancer: current therapies and new targeted treatments. Lancet.2017;389(10066):299-311.

2. Okabe H., Aoki K., Yogosawa S., et al. Downregulation of CD24 suppresses bone metastasis of lung cancer. Cancer Sci.2018;109(1):112-20.

3. Hsu T. Educational initiatives in geriatric oncology - Who, why, and how? J Geriatr Oncol. 2016; 7(5):390-6.

4. Granger A., Mott R., and Emambokus N. Is Aging as Inevitable as Death and Taxes? Cell Metab.2016;23(6):947-8.

5. Lopez-Otin C., Blasco M.A., Partridge L., et al. The hallmarks of aging. Cell.2013; 153(6):1194-217.

6. Sonnenschein C. and Soto A.M. The aging of the 2000 and 2011 Hallmarks of Cancer reviews: a critique. J Biosci. 2013; 38(3):651-63.

7. Alarcon C.R. and Tavazoie S.F. Cancer: Endothelial-cell killing promotes metastasis. Nature.2016;536(7615):154-5

8. Deanfield J.E., Halcox J.P., and Rabelink T.J. Endothelial function and dysfunction: testing and clinical relevance. Circulation. 2007; 115(10):1285-95.

9. Oakley R. and Tharakan B. Vascular hyperpermeability and aging. Aging Dis.2014;5(2):114-25.

10. Herrera M.D., Mingorance C., Rodriguez-Rodriguez R., et al. Endothelial dysfunction and aging: an update. Ageing Res Rev. 2010; 9(2):142-52.

11. Aversa A., Bruzziches R., Francomano D., et al. Endothelial dysfunction and erectile dysfunction in the aging man. Int J Urol.2010; 17(1):38-47.

12. Tornavaca O., Chia M., Dufton N., et al. ZO-1 controls endothelial adherens junctions, cell-cell tension, angiogenesis, and barrier formation. J Cell Biol.2015; 208(6):821-38.

13. Shen L., Weber C.R., Raleigh D.R., et al. Tight junction pore and leak pathways: a dynamic duo. Annu Rev Physiol. 2011;73:283-309.

14. Minakami M., Kitagawa N., Iida H., et al. p38 Mitogen-activated protein kinase and c-Jun NH2-terminal protein kinase regulate the accumulation of a tight junction protein, ZO-1, in cell-cell contacts in HaCaT cells. Tissue Cell.2015; 47(1):1-9.

15. Cai H., Liu W., Xue Y., et al. Roundabout 4 regulates blood-tumor barrier permeability through the modulation of ZO-1, Occludin, and Claudin-5 expression. J Neuropathol Exp Neurol. 2015;74(1):25-37.

16. Guntaka S.R., Samak G., Seth A., et al. Epidermal growth factor protects the apical junctional complexes from hydrogen peroxide in bile duct epithelium. Lab Invest.2011;91(9):1396-409.

17. Zhang Y., Han Y., Zhao Y., et al. DT-13 Ameliorates TNF-alpha-Induced Vascular Endothelial Hyperpermeability via Non-Muscle Myosin IIA and the Src/PI3K/Akt Signaling Pathway. Front Immunol. 2017; 8:925. 
18. Amy S. Clark, Kip A. West, Peter M. Blumberg, et al. Altered Protein Kinase C (PKC) Isoforms in Non-Small Cell Lung Cancer Cells. Cancer Research.2003; 63(4):780-6.

19. Mondrinos M.J., Zhang T., Sun S., et al. Pulmonary endothelial protein kinase C-delta (PKCdelta) regulates neutrophil migration in acute lung inflammation. Am J Pathol.2014;184(1):200-13.

20. Rosenzweig T., Aga-Mizrachi S., Bak A., et al. Src tyrosine kinase regulates insulin-induced activation of protein kinase C (PKC) delta in skeletal muscle. Cell Signal.2004; 16(11):1299-308.

21. Reyland M.E. and Jones D.N. Multifunctional roles of PKCdelta: Opportunities for targeted therapy in human disease. Pharmacol Ther. 2016;165:1-13

22. Fan R., Han Y., Han H., et al. DT-13 ameliorates TNF-alpha-induced nitric oxide production in the endothelium in vivo and in vitro. Biochem Biophys Res Commun.2018; 495(1):1175-1181.

23. Wei X.H., Lin S.S., Liu Y., et al. DT-13 attenuates human lung cancer metastasis via regulating NMIIA activity under hypoxia condition. Oncol Rep. 2016; 36(2):991-9.

24. Y W. Novel cytotoxic steroidal saponins from the roots of Liriope muscari (Decne.) L.H. Bailey. RSC Advamces. 2017; 7:13696.

25. Hakanpaa L., Sipila T., Leppanen V.M., et al. Endothelial destabilization by angiopoietin-2 via integrin beta1 activation. Nat Commun. 2015; 6:5962.

26. Van Itallie C.M., Fanning A.S., Bridges A., et al. ZO-1 stabilizes the tight junction solute barrier through coupling to the perijunctional cytoskeleton. Mol Biol Cell.2009;20(17):3930-40.

27. Azarnia R., Reddy S., Kmiecik T.E., et al. The cellular src gene product regulates junctional cell-to-cell communication. Science. 1988; 239(4838):398-401.

28. Todoric J., Antonucci L., and Karin M. Targeting Inflammation in Cancer Prevention and Therapy. Cancer Prev Res (Phila).2016;9(12):895-905.

29. Nenu I., Tudor D., Filip A.G., et al. Current position of TNF-a in melanomagenesis. Tumor Biology.2015; 36(9):6589-602.

30. Wang H., Liu J., Hu X., et al. Prognostic and Therapeutic Values of Tumor Necrosis Factor-Alpha in Hepatocellular Carcinoma. Medical Science Monitor International Medical Journal of Experimental \& Clinical Research. 2016; 22:3694-704.

31. Jafri M.A., Al-Qahtani M.H., and Shay J.W. Role of miRNAs in human cancer metastasis: Implications for therapeutic intervention. Semin Cancer Biol. 2017.44:117-31

32. Cedervall J., Dimberg A., and Olsson A.K. Tumor-Induced Local and Systemic Impact on Blood Vessel Function. Mediators Inflamm.2015; 2015:418290.

33. Zinger A., Cho W.C., and Ben-Yehuda A. Cancer and Aging - the Inflammatory Connection. Aging Dis. 2017; 8(5):611-27.

34. Ferrara R., Mezquita L., Auclin E., et al. Immunosenescence and immunecheckpoint inhibitors in non-small cell lung cancer patients: Does age really matter? Cancer Treat Rev.2017; 60:60-8.

35. Suda K., Tomizawa K., Mizuuchi H., et al. Genetic and Prognostic Differences of Non-small Cell Lung Cancer between Elderly Patients and Younger Counterparts. Aging Dis.2012; 3(6):438-3.

36. Martin T.A. The role of tight junctions in cancer metastasis. Seminars in Cell \& Developmental Biology. 2014; 36:224-31.

37. Susanne M. Krug, Jörg D. Schulzke, and Fromm M. Tight junction, selective permeability, and related diseases. Seminars in Cell \& Developmental Biology,.2014;36:166-76.

38. Schossleitner K, Rauscher S, Groger M, et al. Evidence That Cingulin Regulates Endothelial Barrier Function In Vitro and In Vivo. Arterioscler Thromb Vasc Biol. 2016; 36(4):647-54.

39. Srinivasan B., Kolli A.R., Esch M.B., et al. TEER measurement techniques for in vitro barrier model systems. J Lab Autom.2015; 20(2):107-26.

40. Van Itallie C.M. and Anderson J.M. Architecture of tight junctions and principles of molecular composition. Semin Cell Dev Biol. 2014; 36:157-65.

41. Van Itallie C.M., Aponte A., Tietgens A.J., et al. The N and C termini of ZO-1 are surrounded by distinct proteins and functional protein networks. J Biol Chem.2013; 288(19):13775-88.

42. Hu G., Place A.T., and Minshall R.D. Regulation of endothelial permeability by Src kinase signaling: vascular leakage versus transcellular transport of drugs and macromolecules. Chemico-Biological Interactions. 2008; 171(2):177-189.

43. Gulsah C., Arzum E., and Fehmi M. Electrochemical investigation of the interaction between topotecan and DNA at disposable graphite electrodes. Bioelectrochemistry.2015; 102:21-8.

44. Horita N., Yamamoto M., Sato T., et al. Topotecan for Relapsed Small-cell Lung Cancer: Systematic Review and Meta-Analysis of 1347 Patients. Scientific Reports.2015;5(8):2894-904.

45. Kim J.-H., Kim J.H., Jun H.-O., et al. Inhibition of Protein Kinase C $\delta$ Attenuates Blood-Retinal Barrier Breakdown in Diabetic Retinopathy. The American Journal of Pathology.2010;176(3):1517-24.

46. Mullin J M, Kampherstein J A, and Laughlin K V. Overexpression of protein kinase C-delta increases tight junction permeability in LLC-PK1 epithelia. American Journal of Physiology.1998;275(2):544-554.

47. Kou J., Sun Y., Lin Y., et al. Anti-inflammatory activities of aqueous extract from Radix Ophiopogon japonicus and its two constituents. Biol Pharm Bull. 2005;28(7):1234-8.
48. Kou J, Tian $\mathrm{Y}$, Tang $\mathrm{Y}$, et al. Antithrombotic activities of aqueous extract from Radix Ophiopogon japonicus and its two constituents. Biol Pharm Bull. 2006;29(6):1267-70.

49. Lin S.S., Fan W., Sun L., et al. The saponin DT-13 inhibits gastric cancer cell migration through down-regulation of CCR5-CCL5 axis. Chin J Nat Med. 2014; 12(11):833-40.

50. Zhang Y., Sun M., Han Y., et al. The saponin DT-13 attenuates tumor necrosis factor-alpha-induced vascular inflammation associated with Src/NF-small ka, CyrillicB/MAPK pathway modulation. Int J Biol Sci.2015;11(8):970-81.

51. Li H., Sun L., de Carvalho E.L., et al. DT-13, a saponin monomer of dwarf lilyturf tuber, induces autophagy and potentiates anti-cancer effect of nutrient deprivation. Eur J Pharmacol. 2016;781:164-72. 